facts required by the designer, thereby saving him from the inconvenience of continual reference to bulky volumes of tables. A minor omission is a table of heats of solution, while a wolcome item rarely found in British books is an indication of the price of the main components of the plant. Absorption calculations unfortunately require the use of a great many symbols which are difficult to remember; but the reader is helped in the present book not only by a six-page summary at the end of the volume but also by an explanatory list after each important formula, a practice much to be commended. Units are often a source of confusion : the C.G.S., British and metric systems are all used, but the first is confined to the laboratory section. Both British and metric values are given in the tables, the figures being set out with such clarity that a mistake is well-nigh impossible.

One omission, no doubt intentional, is greatly to be regretted-the complete absence of data for the performance of existing large towers and comparison with calculated values. This tends to impart an academic atmosphere to the book, despite its obviously practical nature. The authors emphasize that large towers are difficult to test, that some of the design methods recommended are still tentative, and that it is sometimes desirable to introduce factors of safety ; but a few definite figures for the discrepancies actually found would indicate the reliance to be placed on the calculations. Apart from this, the book is a model of the way in which to treat a complex chemical engineering subject and is a particularly good example of the application of science to industry. All chemical engineers will adopt it as a standard work of reference, and all chemical manufacturers should study it. H. E. Watson

\section{NAPHTHOIC ACIDS AND THEIR DERIVATIVES}

\section{Elsevier's Encyclopædia of Organic Chemistry}

Edited by F. Radt. Series 3 : Carboisocyclic Condensed Compounds. Vol. 12B: Naphthalene. $(A)$ Compounds Containing One Naphthalene Nucleus. Naphthoic Acids and Their Halogen, Nitrogen, and Hydroxyl Derivatives. Pp. 3965-4560. (Amsterdam : Elsevier Publishing Company; London: CleaverHume Press, Ltd., 1953.) £21 net. (Series Subscriber, £18 10s.; Complete Subscriber, £16.)

THIS seventh part of Vol. $12 B$ makes a useful addition to the section of the Encyclopædia dealing with naphthalene derivatives. The seven parts together already constitute an impressive survey of naphthalene chemistry, but the end is not yet in sight. Part 7 is concerned with the two naphthoic acids and their hydrides and homologues, together with the usual types of acid derivatives, and various substitution products containing halogen, nitrogenous groups, hydroxyl and alkoxyl. Polycarboxylic acids derived from naphthalene will find a place, presumably, in Part 8. As is usual with such a method of treatment, the result is an assembly of information about an assortment of compounds which will appeal to a variety of tastes.

For the natural product chemist there is an interesting review of the recent chemistry of naturally occurring lactones derived from naphthoic acids. These comprise the conidendrins and the constituents of 'podophyllin'. As regards the latter, the structural relationships between podophyllotoxin and picropodophyllin and their derivatives are set forth in a characteristically clear chart of formulæ. These substances have aroused some interest among biologists on account of their destructive action on certain pathological growths. The chemical reader who consults the index may well wonder what is an 'oncolytic' compound. If he refers to the text, he will find that it is a substance with tumour-damaging activity.

For the dyestuffs chemist there are surveys of aminonaphthoic and hydroxynaphthoic acids. The anilide of 2-hydroxy-3-naphthoic acid (Naphthol $A S$ ) and its applications are fully discussed; many azo dyes derived from this and related compounds are described, and there is a table occupying fifteen pages which summarizes the properties of the many known arylamides of 2-hydroxy-3-naphthoic acid. For the pharmacological chemist there are descriptions of many compounds with local anæsthetic activity derived from the aminonaphthoic acids.

There are the usual references to physical constants, including optical data, and to biological properties as far as these have been recorded. For l-naphthonitrile, for example, the ultra-violet absorption maxima and Raman frequencies are given, as well as the fluorescence, phosphorescence and magnetic properties, the dielectric constant, the heat of combustion and the density. Its polyploidogenic action is also mentioned. The only misprint which has been noted is an obvious one, in a heading on p. 4009. The high standard of previous parts of this Encyclopædia is well maintained. J. W. Cook

\section{BASIC DYNAMICS FOR STUDENTS OF AERONAUTICS}

Introduction to Aeronautical Dynamics

By Prof. Manfred Rauscher. Pp. xv +664 . (New York: John Wiley and Sons, Inc.; London : Chapman and Hall, Ltd., 1953.) 96s. net.

ARONAUTICS is, with the possible exception of astronomy, the subject in which the greatest and most diverse applications of classical mechanics are made. These applications cover problems of the dynamics of particles and of rigid and deformable bodies, oscillations of many kinds and the whole field of the mechanics of fluids. Investigations of great difficulty and much technical importance arise in which the system consists of a deformable body (aircraft) in motion through a viscous and compressible fluid (air). Questions of the stability of motion are of great importance, while thermodynamic considerations are essentially involved in the problems of propulsion and of high-speed flight in general. All this implies that aeronautical scientists and engineers must be well versed in dynamical techniques, some of which have indeed been specially devised for the treatment of aeronautical problems, while students must have a thorough training in dynamical fundamentals. It is these fundamentals which the book under review aims to provide.

Dynamical theory may be regarded as composed of three parts : kinematic theory, dynamical principles, and mathematical techniques for the solution of problems. Kinematic theory is based only on pure geometry and the concept of time and is thus not, 